\title{
Self-Efficacy in Diabetic Amputees: An Empirical Analysis
}

\author{
Geeta Sunkarapalli ${ }^{1}$, Sameeha Fatima $^{2}$, Swati Agarwal ${ }^{3}$ \\ ${ }^{I}$ (Assistant Professor, Department of Psychology, St. Francis College for Women, Begumpet, Hyderabad, India) \\ ${ }_{2}^{2}$ (Student, Department of Psychology, St. Francis College for Women, Begumpet, Hyderabad, India) \\ ${ }_{3}^{3}$ (Assistant Professor, Department of Psychology, St. Francis College for Women, Begumpet, Hyderabad, India)
}

\begin{abstract}
Self-efficacy according to Bandura (1997) is a person's belief in his or her ability to succeed in a particular situation. A relatively lower level of Self-efficacy can be seen in amputees as they lose a part of their body (Bosse et al., 2002) and diabetes is one of the major precursor to amputation (Viswanathan, 2007). The study investigated the effect of gender, family type and marital status on the levels of Self-efficacy in diabetic amputees. A purposive sampling method was employed to select participants belonging to the age range of 5060 years. A sample of 60 participants (30 men and 30 women) was approached through hospitals. They were administered the Chronic Disease Self-efficacy Scale developed by Lorig et al. (1996). The data was subjected to t-test. The results indicated a significant effect of gender on the level of Self-efficacy as men managed symptoms of their disease better than women. A significant effect of the family type was seen as participants living in nuclear families had more Self-efficacy to get information about the disease and also they were able to manage symptoms better than those living in joint families. Marital status had a significant effect on the Selfefficacy as married participants exercised more and managed their symptoms better than widowed participants. This study throws light on the difficulties faced by amputees and also makes diabetic patients aware of the risk factors of their disease and that they must undertake steps to prevent any further complications.
\end{abstract}

Keywords:-Self-efficacy, Diabetic Amputees.

\section{INTRODUCTION}

Self-efficacy is the belief in one's capabilities to organize and execute the courses of action required to manage prospective situations. In other words, it is a person's belief in his or her ability to succeed in a particular situation (Bandura, 1997). Self-efficacy is a belief in one's ability to use skills in realistic contexts, and a belief that the use of those skills will produce the desired outcomes (Lorig, 1996). The level of selfefficacy of a person indicates whether he or she can rise up to accomplish a goal or give up in defeat in the face of challenges. Self-efficacy or people's perception of their capabilities for performance, are a cognitive mechanism underlying behavioural change (Cervone, 2013). It begins to develop during infancy and continues to develop throughout life as we continually integrate information during our lifespan. Self-efficacy is developed, according to Bandura, through the following sources that help us integrate information: mastery experiences, social modelling, social persuasion and psychological responses. Self-efficacy plays a crucial role in psychological adjustment, psychological problems, physical health as well as self-guided behaviour change strategies (Krein, et al., 2007), self-care and self-management in chronic diseases ().

Middleton (2007) found that self-efficacy (expectations of daily living) and pain in people with spinal cord injuries and their quality of life shows that a combination of low Self-efficacy and pain intensity was associated with an increased reduction in Quality of life compared with reductions seen for these factors by themselves.According to Kato (2016), growing qualitative evidence reveals that many patients with chronic illnesses struggle to rebuild a positive self-image after diagnosis while attempting to find a balance between their current physical status and their ongoing social duties. One factor destabilizing patients' identities is selfstigma, which seems to affect their behavioural goals through decreased self-efficacy. Results showed that to optimize treatment outcomes, patients' self-stigma should be minimize, whereas their self-efficacy should be enhanced. Research has shown that the ongoing rate of diabetes-related amputation remain significant despite the existence of preventive methods and that amputation in most cases can be prevented. A study assessed the relationship between the level of self-efficacy and performance of foot self-care in those with diabetes as they relate to the prevention of lower extremity population (LEA). Results showed no significant correlation between the level of self-efficacy and performance of foot self-care behaviours. Statistical significance, however, was found between foot self-care behaviours and gender with males scoring higher than females. (Wendling, 2015). According to a study done on adolescents, individuals with insulin dependent diabetes mellitus (IDDM) face increasing responsibilities for managing their own treatment. Although they showed similar expectancies for diabetes self-efficacy. Girls had significantly positive correlations between their Self-efficacy for Diabetes Scale (SED) score and metabolic control, whereas boys did not (Youkilis, 1987). 
Diabetes mellitus is the second major cause of lower limb amputation after traumatic accidents in India. According to studies conducted by Vishwanathan et al, in India, about $90 \%$ of the people had diabetic foot infection, $30 \%$ of them underwent a major amputation and the rest $70 \%$ a minor one.

Amputation refers to the process of removal of any of the body part. The causes can be natural disasters like earthquakes, accidents or due to any other medical reasons, carried out in order to improve the life of the individual. The psychological aspects of amputation leads to many problems that must be approached in a perceptive manner. One must try to understand that the life of an amputee is disrupted severely in a multifaceted manner, he loses much more than a limb. One of the major precursors of amputation is inadequate treatment of diabetic foot ulcers which can lead to a lower limb amputation. In diabetes, adjustment to amputation and prosthesis; physically and psychologically, are reported to be associated with Quality of Life in people with amputation (MacLachlen and Gallagher, 2004).

Amputation is referred to as "triple insult" as it brings loss of function, loss of sensation and loss or change of body image (Horne et al, 2009). The quality of life is poor in traumatically handicapped patients and it is worse when they have psychiatric morbidity. (Malik et al, 2010). A study done by Narang et.al show that age negatively influenced functional independence in lower limb amputees, and also found out that below limb amputees were comparatively more independent than above knee and bilateral amputees.

A study conducted on soccer players in the Amputee World Cup indicated that Self-efficacy has a reciprocal relationship with performance. High self-efficacy and successful performance are associated with several psychological skills like relaxation, used in training and competition in the field of sports (Lowther et.al, 2002). According to another study by Lackner, Jefferey,Carosella, Marie, Feuerstein and Micheal in 1996 showed that Self-efficacy was significantly related to gender physical function. Also, Self-efficacy, pain intensity, and gender correlated consistently with physical performance. Self -efficacy is an important correlate of physical activity for girls. But boys are more physically active because they have more self-efficacy for physical activity (Spence JC, Blanchard CM, Clark M, Plotnikoff RC, Storey K, McCargar L. 2010). The clinical impression that spinal cord injured and traumatic lower limb amputees are more prone to develop degenerative diseases was investigated by comparing the prevalence of hypertension, ischaemic heart disease, and diabetes mellitus in these two patient groups with the prevalence of these diseases among a group of healthy age-matched controls. Results showed a significant increased incidence of hypertension and ischaemic heart disease among those with spinal cord injuries compared with their controls; and among the amputees, a significant increased incidence of ischaemic heart disease and of diabetes mellitus (Yekutiel, 1989).

Among the variables predicting more negative impact on sexual activity were older age, being unmarried, and greater feelings of amputation-fostered self-consciousness in intimate situations. Higher levels of perceived negative impact of amputation on sexual activity, in turn, were related to more symptoms of depression, and in fact, impact on sexual activity emerged as the most consistent predictor of depressive symptomatology (Williamson et al., 1996). Studies suggest that lower limb amputations for peripheral arterial disease are performed predominantly on an elderly population with poor social support and concomitant medical problems.Amputees reported significantly more problems with mobility, social isolation, lethargy, pain, sleep and emotional disturbance than controls (Pell et al., 1993).

\subsection{Objectives}

The objective of the study was to determine if there is a difference in the levels of chronic disease self-efficacy between men and women diabetic amputees. Differences in the levels of self-efficacy between married and widowed diabetic amputees and diabetic amputees living in joint and nuclear families was also analysed.

\section{METHOD}

\subsection{Research Design}

The present study adopts a between group design to assess the difference in the levels of chronic disease selfefficacy in diabetic amputees based on gender - men and women; family type - diabetic amputees living in joint and nuclear families; and marital status - married and widowed.

\subsection{Participants}

Non-probability purposive sampling method was used to obtain a sample of 60 diabetic amputees with equal number of men and women. The participants were approached through hospitals, mainly the public or government run hospitals with majority of the participants being in patients. The sample size was 60 out of which 30 were men and 30 were women. The sample included patients within the age range of 50-60 years who were diabetic amputees and had been amputated in the last year. Those who had undergone amputation due to any other reason, like road or railways accidents or any other reason, except diabetes and those who had undergone amputation more than a year earlier were excluded from the sample.

\subsection{Instrument}

The Chronic Disease Self-efficacy Scale developed by Lorig et al. (1996) was used in the study. The scale has 33 items, each one to be responded on a 10 point Likert scale ranging from 'not at all confident' to 'totally 
confident'. The scale has 10 sub-scales which are as follows: exercise regularly scale ( 3 items), get information about the disease item (1 item), obtain help from community, family, friends scale (4 items), communicate with physician scale (3 items), manage disease in general scale (5 items), do chores scale (3 items), social/recreational activities scale (2 items), manage shortness of breath item (1 item), manage symptoms scale (5 items), and control/manage depression scale (6 items). Higher scores on the sub scales indicate higher levels of self-efficacy in the specific domain. The scale is reliable with the internal consistency scores ranging from 0.77 to 0.92 . Test-retest reliability was also established with the values ranging from 0.72 to 0.89 . The scale was translated into two vernacular languages, that is, Telugu and Urdu, which were used as and when required.

\subsection{Procedure}

Various hospitals in the twin cities of Hyderabad and Secunderabad were approached and their permission was obtained to carry out the study in their hospitals. Patients fulfilling the inclusion criteria were approached and informed about the purpose of the study. After obtaining the informed consent, a personal information schedule and the self-efficacy scale were administered. In addition to the written instructions, the participants were also instructed verbally and were encouraged to seek clarification on any aspect related to the study. The time taken to complete the scale was approximately 5-6 minutes per participant. The data collected was analysed using descriptive statistics and independent sample $t$ test.

\section{RESULTS}

Table 1. Mean, Standard Deviation and t-test values for Self-efficacy and gender

\begin{tabular}{|c|c|c|c|c|c|}
\hline \multirow[t]{3}{*}{ Subscales } & \multicolumn{3}{|c|}{ Gender } & & \\
\hline & \multicolumn{2}{|l|}{ Men } & \multicolumn{3}{|c|}{ Women } \\
\hline & Mean & SD & Mean & SD & t-test \\
\hline Exercise regularly & 1.87 & 0.59 & 1.64 & 0.59 & 1.50 \\
\hline $\begin{array}{l}\text { Get information } \\
\text { about the disease }\end{array}$ & 4.90 & 2.20 & 3.93 & 2.03 & 1.70 \\
\hline $\begin{array}{l}\text { Obtain help from } \\
\text { community, } \\
\text { family friends }\end{array}$ & 5.29 & 5.00 & 1.59 & 1.92 & 0.56 \\
\hline $\begin{array}{l}\text { Communication } \\
\text { with physician }\end{array}$ & 7.05 & 2.60 & 6.60 & 2.50 & 0.56 \\
\hline $\begin{array}{l}\text { Manage disease in } \\
\text { general }\end{array}$ & 14.99 & 1.26 & 4.76 & 1.40 & 0.65 \\
\hline Do chores & 3.08 & 1.23 & 3.05 & 1.10 & 0.11 \\
\hline $\begin{array}{l}\text { Social/recreational } \\
\text { activities }\end{array}$ & 5.08 & 2.17 & 4.60 & 1.85 & 0.93 \\
\hline $\begin{array}{l}\text { Manage } \\
\text { symptoms }\end{array}$ & 4.58 & 1.17 & 4.10 & 0.97 & $1.73^{*}$ \\
\hline $\begin{array}{l}\text { Manage shortness } \\
\text { of breath }\end{array}$ & 4.13 & 1.83 & 3.73 & 1.52 & 0.92 \\
\hline $\begin{array}{l}\text { Control/manage } \\
\text { depression }\end{array}$ & 4.76 & 1.71 & 4.15 & 1.73 & 1.36 \\
\hline
\end{tabular}

$* \mathrm{p}<0.05$

H1 was partially accepted and largely rejected as there is a significant $t$ value only in one subscale.

The results in table 1 show that men had higher scores than women in the managing symptoms subscale. No differences were seen between men and women in the other dimensions of chronic disease self-efficacy scale. Figure 1. bar graph showing mean values of men and women diabetic amputees on the subscales of chronic disease self-efficacy scale 


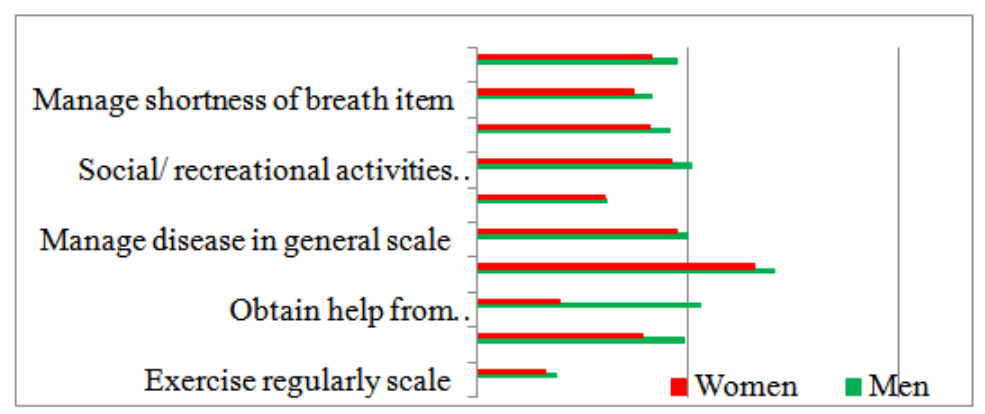

Table 2. Mean, Standard Deviation and t-test values for Self-efficacy and family type

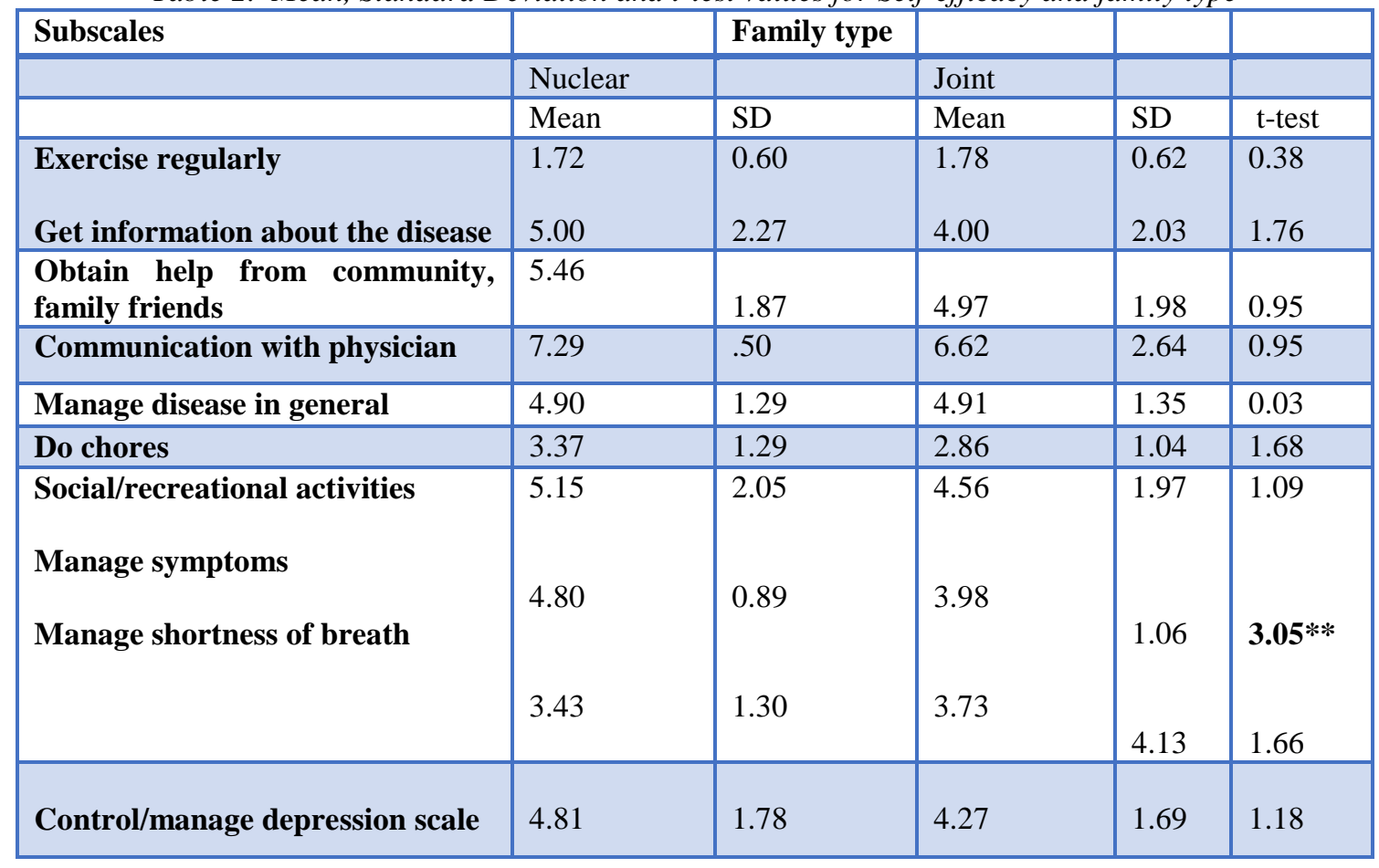

$$
\begin{aligned}
& * \mathrm{p}<0.05 \\
& * * \mathrm{p}<0.01
\end{aligned}
$$

H2 was partially accepted as two of the subscales showed significant t-test values.

Table 2 shows that there is a significant difference in the levels of two of the dimensions of self-efficacy among diabetic amputees living in joint and nuclear families. Participants living in nuclear families reported scores than participants living in joint families for the 'manage symptoms' subscale and the 'get information about the disease item'

Figure 2. bar graph showing mean values of diabetic amputees living in joint and nuclear families on the subscales of chronic disease self-efficacy scale

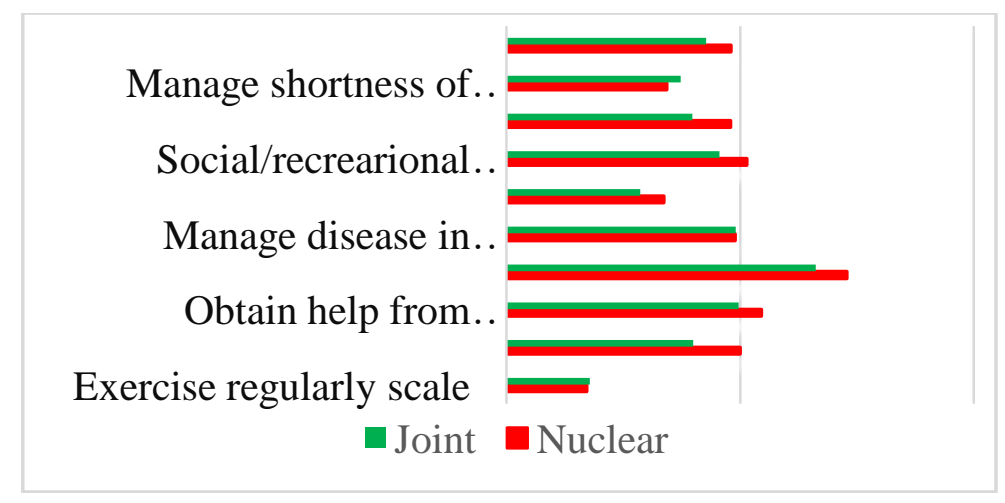


Table 3. Mean values, Standard Deviation, and t-test values for Self-efficacy and marital status

\begin{tabular}{|c|c|c|c|c|c|}
\hline \multirow[t]{3}{*}{ Subscales } & \multicolumn{4}{|c|}{ Marital status } & \multirow[b]{3}{*}{ t-test } \\
\hline & \multicolumn{2}{|c|}{ Married } & \multicolumn{2}{|c|}{ Widowed } & \\
\hline & Mean & $\mathrm{SD}$ & Mean & SD & \\
\hline Exercise regularly & 1.90 & 0.62 & 1.49 & 0.47 & $2.65 * *$ \\
\hline $\begin{array}{l}\text { Get information } \\
\text { about the disease }\end{array}$ & 4.33 & 2.01 & 4.57 & 2.44 & 0.40 \\
\hline $\begin{array}{l}\text { Obtain help from } \\
\text { community, } \\
\text { family friends }\end{array}$ & 5.34 & 1.80 & 4.78 & 2.14 & 1.07 \\
\hline $\begin{array}{l}\text { Communication } \\
\text { with physician }\end{array}$ & 7.12 & 2.50 & 6.38 & 2.60 & 1.07 \\
\hline $\begin{array}{l}\text { Manage disease in } \\
\text { general }\end{array}$ & 5.10 & 1.37 & 4.45 & 1.15 & $1.85 *$ \\
\hline Do chores & 3.14 & 1.14 & 2.93 & 1.21 & 0.66 \\
\hline $\begin{array}{l}\text { Social/recreational } \\
\text { activities }\end{array}$ & 5.07 & 1.98 & 4.40 & 2.05 & 1.24 \\
\hline $\begin{array}{l}\text { Manage } \\
\text { symptoms }\end{array}$ & 4.43 & 1.02 & 4.17 & 1.22 & 0.88 \\
\hline $\begin{array}{l}\text { Manage shortness } \\
\text { of breath }\end{array}$ & 3.87 & 1.54 & 4.04 & 1.96 & 0.38 \\
\hline $\begin{array}{l}\text { Control/manage } \\
\text { depression }\end{array}$ & 4.52 & 1.65 & 4.32 & 1.91 & 0.43 \\
\hline
\end{tabular}

$* \mathrm{p}<0.05$

$* * \mathrm{p}<0.01$

H3 was partially accepted as two of the subscales showed significant t-test values

Results comparing the levels of self-efficacy between married and widowed participants show that married diabetic amputees had higher scores for the dimensions of 'exercise regularly' and 'manage disease in general' subscales.

Figure 3. bar graph showing mean values of married and widowed diabetic amputees on the subscales of chronic disease self-efficacy scale

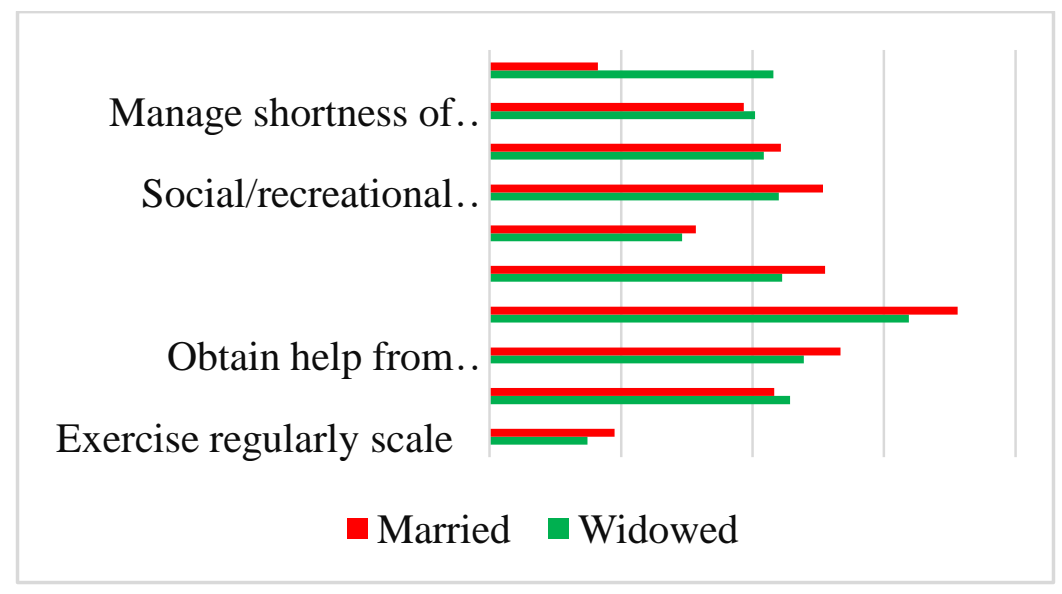




\section{DISCUSSION}

The purpose of the study was to test if there is a significant difference in the levels of Self-efficacy among men and women Diabetic amputees and also to find out if their marital status and family type had any effect. The alternate hypotheses could not be completely accepted as the results showed significant differences only in a few dimensions and the rest of the dimensions showed no significant differences.

Though no gender differences were found in most of the domains of chronic disease self-efficacy, men diabetic amputees reported being better at managing symptoms related to their disease when compared to women diabetic amputees. Earlier studies have also found mixed results with some reporting no gender differences in self-efficacy (Shead, 2005) and others reporting higher self-efficacy in men than women (Wendling and Beadle, 2015; Yusuf et al., Burner, Menchine, Taylor and Arora, 2013). Wendling and Beadle also found similar results in their study, with men showing higher self-efficacy and greater diabetic foot selfcare behaviour than women. Surprisingly in this study self-efficacy and diabetic foot self-care were not found to be related to one another. Yusuf et al (2013) conducted an intervention study focusing on providing psychoeducation on diabetes self-management to Bangladeshi immigrants living in the US. The study found a significant increase in the levels of self-efficacy post intervention particularly in women. In this study men had higher levels of self-efficacy at the beginning and end of intervention when compared to women. The study by Burner, Menchine, Taylor and Arora () also found gender differences in the areas of self-efficacy changed from a mobile health intervention program with men displaying increased self-efficacy and women reporting increased knowledge. The present study also shows that married participants have significantly higher selfefficacy than widowed diabetic amputees in the domains of 'exercise regularly' and 'manage disease in general'.Sherbourne and colleagues' (1990) study on chronic disease patients supported an indirect effect of marital status on mental health through social support, but did not support a relationship, direct or indirect, of either marital status or social support with physical health outcomes.Results also show that diabetic amputees living in nuclear families have higher self-efficacy in the domains of 'managing symptoms' and 'getting information about the disease' than those living in joint families. Ford et al. (1998) have found that African Americans tend to rely more heavily than whites on their informal social networks to meet their disease management needs and that social support is significantly associated with improved diabetes management among members of this population. Compared to people who are married, those who are unmarried have higher levels of psychological distress, and further married people have better overall well-being which is strong and consistent when compared to people who are divorced, single or separated (Gore and Mangione, 1983) Social support, especially emotional support, has been found to decrease depression, anxiety, and other psychological problems (Mirowsky and Ross, 1989). Thus, it is evident that chronic disease self-efficacy in diabetic amputees is influenced in specific domains by gender, marital status, and family type. Though the study is limited by its small sample size, cross sectional nature and lack of controls consisting of diabetics who had not undergone amputation, the findings of this study have significant value. Self-efficacy in diabetics plays a major role in diabetes self-care, which has been found across numerous studies. Future studies can look into developing intervention programs keeping in mind the needs and the difficulties faced by amputees and design an intervention in order to help them in their coping process. As diabetes is one of the major precursors to amputation, diabetic patients must be made aware of the risk factors of their disease and the preventive measures they must undertake to maintain and improve their health status.

\section{IMPLICATIONS}

a. The study throws light on the difficulties faced by amputees and the need to design an intervention in order to help them in their coping process.

b. As diabetes is one of the major precursors to amputation, diabetic patients must be made aware of the risk factors of their disease and the preventive measures they must undertake.

\section{ACKNOWLEDGEMENTS}

I am thankful to Ms. Tina Fernandes, the Head of the Department, St.Francis College, for her constant encouragement. I would like to extend my gratitude to my friends, family and all my well-wishers without whose support I would not have been able to complete my research project. Lastly, I would like to thank all the participants for having cooperated with the process.

\section{REFERENCES}

[1] Bosse, M. J., MacKenzie, E. J., Kellem, J. F., Burgess, A. R., Webb, L. X., Swiontkowski, M.F., ...\& Castillo, R. C. (2002). An analysis of outcomes of reconstruction or amputation after leg-threatening injuries. New England Journal of Medicine, 347(24), 1924-1931.

[2] Bandura, A. (1997). Self-efficacy: the exercise of control. New York: Freeman. 
[3] Lorig K, Stewart A, Ritter P, Gonzalez V, Laurent D, Lynch J.(1996) Outcome measures forhealth education and other health care interventions. Thousand Oaks (CA): Sage Publications.

[4] Cervone, D. (2013). Thinking about self-efficacy. Behavior modification, 24(1), 30-56.

[5] Krein S. L., Heisler, M., Piette, J. D., Butchart, A., \& Kerr, E. A. (2007). Overcoming the

[6] influence of chronic pain on older patients' difficulty with recommended self-management activities. The Gerontologist, 47(1), 61-68.

[7] Middleton et al. (2007). Relationship Between Quality Of Life And Self-Efficacy In Persons With Spinal Cord Injuries, Arch Phys Med Rehabil; 88:: 1643-8.

[8] Kato, A., Fujimaki, Y., Fujimori, S., Isogawa, A., Onishi, Y., Suzuki, R., ... \& Hashimoto, H. (2016). Association between self-stigma and self-care behaviors in patients with type 2 diabetes: a crosssectional study. BMJ Open Diabetes Research \& Care, 4(1), e000156.

[9] Wendling, S., \& Beadle, V. (2015). The relationship between self-efficacy and diabetic foot selfcare. Journal of Clinical \& Translational Endocrinology,2(1), 37-41

[10] Youkilis, Brink and Hauser (1987) Self-Efficacy in Adolescent Girls and Boys with Insulin -Dependent Diabetes Mellitus. Diabetes Care 10:324-29, 1987Amir, N (2004). The plight of working women in Pakistan: advantages and disadvantages of a joint family system. Social Policy and Development Centre, 2004.

[11] Viswanathan V. \&Kumpatla S., (2011). Pattern and causes of amputation in diabetic patients-a multicentric study from India. J Assoc Physicians India, 59, 148-151.

[12] Viswanathan V. (2007) The Diabetic Foot: Perspectives from Chennai, South India. Int J Low Extrem Wounds 2007; 6(1):34-6.

[13] MacLachlan M, Gallagher P.(2004) The Trinity Amputation and Prosthesis Experience Scalesand Quality Of Life in People with Lower Limb Amputation. Arch Phys Med Rehabil; 85(5): 730-6.

[14] Horne CE, Neil JA.(2009) Quality of life in inpatients with prosthetic legs: a comparison study. J ProsthetOrthot ;21(3):154-9.

[15] Malik P, Garg R, Gulia A, Kumar N, Sidhu B, Sharma K.(2010).Quality of life in post-traumatic orthopedically handicapped patients. Indian J Med Sci 2010;64(5):224-33.

[16] Narang et al., (1984). Functional Capabilities of Lower Limb Amputees. Prosthetic OrthotInt; schunk8(1): 43-51.

[17] Lackner, J. M., Carosella, A. M., \& Feuerstein, M. (1996). Pain expectancies, pain, andfunctional selfefficacy expectancies as determinants of disability in patients with chronic low back disorders. Journal of consulting and clinical psychology, 64(1), 212.

[18] Spence, J. C., Blanchard, C. M., Clark, M., Plotnikoff, R. C., Storey, K. E., \&McCarger, L. (2010). The role of self-efficacy in explaining gender differences in physical activity among adolescents: a multilevel analysis. Journal of physical activity \&health, 7(2), 176.

[19] Yekutiel, M., Brooks, M. E., Ohry, A., Yarom, J., \&Carel, R. (1989). The prevalence of hypertension, ischaemic heart disease and diabetes in traumatic spinal cord injured patients and amputees. Spinal Cord, 27(1), 58-62.

[20] Williamson, G. M., \& Walters, A. S. (1996). Perceived impact of limb amputation on sexualactivity: a study of adult amputees. Journal of sex research, 33(3), 221-230.

[21] Shead, H. E. (2005). Gender Differences in the Self-Efficacy of African Americans with Type II Diabetes: A Secondary Analysis of a Chronic Disease Self-Management Program.

[22] Pell, J. P., Donnan, P. T., Fowkes, F. G. R., \&Ruckley, C. V. (1993). Quality of life following lower limb amputation for peripheral arterial disease .European journal of vascular surgery, 7(4), 448-451.

[23] Yusuf, Y., Riley, L., Alam, G., Haq, M., Taher, M., Wyatt, L., ... \& Islam, N. (2013, November). Gender differences in self efficacy and behavior outcomes among diabetic Bangladeshis in New York City. In 141st APHA Annual Meeting and Exposition (November 2-November 6, 2013). APHA.

[24] Sherbourne, C. D., \& Hays, R. D. (1990). Marital status, social support, and health transitions in chronic disease patients. Journal of Health and Social Behavior, 328-343.

[25] Ford, M. E., Tilley, B. C., \& McDonald, P. E. (1998). Social support among African-Americanadults with diabetes, Part 2: A review. Journal of the National Medical Association, 90(7), 425.

[26] Gore S. and Mangione T., (1989). Social Roles, Sex Roles, and Psychological Distress, Journal Of Health and Social Behaviour 24: 300-312. 